\title{
Implicit Misconceptions in Prospective Mathematics Teachers' Reasoning About Trigonometric Concepts
}

\author{
Priestly Malambo ${ }^{1 *}$ (1)
}

${ }^{1}$ The University of Zambia, Department of Mathematics and Science Education, ZAMBIA

*Corresponding Author: priestly.malambo@unza.zm

Citation: Malambo, P. (2021). Implicit Misconceptions in Prospective Mathematics Teachers' Reasoning About Trigonometric Concepts. Contemporary Mathematics and Science Education, 2(2), ep21011. https://doi.org/10.30935/conmaths/11054

\begin{abstract}
The likelihood of misunderstanding and misrepresenting trigonometric ideas motivated an investigation of implicit misconceptions in prospective mathematics teachers' reasoning about particular trigonometric concepts. To access the participants' implicit misconceptions, a qualitative approach and case study design in particular were employed. Three prospective teachers chosen purposefully composed the sample. The student teachers majored in mathematics and were in the final year of training. Four diagnostic questions based on trigonometry were administered followed by semi-structured interviews. Qualitative analyses of calculations and interview transcripts revealed implicit misconceptions in participants' reasoning. The prospective teachers reasoned that trigonometric equations can be resolved in the same way as conventional algebraic equations. Likewise, they demonstrated an erroneous notion that inverse trigonometric functions are evaluated just like indices. Besides, the participants incorrectly considered elements of domains of trigonometric functions to be synonymous with such functions' extreme values. Overall, prospective teachers' reasoning demonstrated didactical obstacles. It is therefore proposed that mathematics teacher education should include opportunities for prospective teachers to reason about mathematics concepts in a manner that prevents didactical obstacles. Furthermore, mathematics educators should engage in instructional practices which facilitate prospective teachers' acquisition of in-depth understanding of mathematics conceptual relationships and differences.
\end{abstract}

Keywords: implicit misconceptions, trigonometric concepts, conceptual relationships and differences, prospective mathematics teachers

Received: 17 Jan. $2021 \bullet$ Accepted: 1 May 2021

\section{INTRODUCTION}

Mathematics is a core subject in most countries' secondary education curricula. This could be due to the subject's presumed benefits to learners and nations at large. It is incontestable that mathematics teachers' understanding of specific mathematics concepts has influence on their learners' comprehension of those mathematics concepts. Although teachers may continuously modify their understanding of concepts during the practice of teaching, they acquire their initial formal understanding through learning experiences as pupils. However, the mathematics concepts as learned in school cannot be relied upon to equip teachers with the kind of understanding required for them to be effective teachers of the same concepts. This view is persuasive because the teaching that goes on in school mathematics classrooms has objectives which are not directly linked to a goal of training would be teachers of mathematics. By implication, the mathematics subject matter which teachers of mathematics may have studied as pupils in school is not sufficient for effective teaching. Therefore, teachers' meaningful understanding of mathematics concepts should be developed during their training as teachers of mathematics (Malambo, 2020). In this vein, mathematics teacher education affords an appropriate platform to begin to strengthen prospective teachers' mathematics subject matter knowledge coupled with how they could unpack the mathematics concepts for pupils' conceptual understanding.

Notwithstanding the foregoing, there are other factors such as policy documents which impact the teaching that goes on in classrooms. For example, the Zambian education curriculum framework (Ministry of Education, 2013a) requires teachers to conduct their teaching in social constructivist environments that allow for learners to construct their understanding socially (Ferguson, 2007). If teachers are to allow classroom cultures of open mathematical discussions between them and learners and among learners, it is imperative that they acquire in-depth understanding of the subject matter taught. Teachers of mathematics can effectively assist learners to realize curricula aspirations when they have the correct understanding of the mathematics concepts taught. These views speak to the significance of paying attention to the understandings of mathematics concepts which teachers acquire during their initial teacher training phase. Thus, what prospective teachers (student teachers) understand of the school mathematics concepts and how they reason about those concepts are critical aspects which are 
expected to be emphasized on in mathematics teacher education programs. Furthermore, what is underscored is a necessity for investigations of the barriers to prospective teachers' acquisition of conceptual understandings. Such investigations could provide a basis for improvising teaching strategies which can facilitate elimination of possibilities for learners' development of barriers to conceptual understanding.

Among the mathematics topics that are taught in the Zambian secondary school education system is trigonometry (Ministry of Education, 2013b). Reasons for teaching trigonometry include development in learners of abilities for clear mathematical thinking and expression, development of learners' mathematical knowledge and skills and enhancing their understanding of mathematics concepts. Specific concepts encapsulated in the Zambian secondary school curriculum include trigonometric ratios, the sine and cosine rules together with their use, trigonometric functions and their graphs, and trigonometric equations (Ministry of Education, 2013b). Some of these concepts formed the basis of an investigation into prospective teachers' implicit misconceptions as they reasoned about trigonometric concepts. A study focusing on prospective teachers' misconceptions was necessary because misconceptions are an impediment to conceptual understanding (Minstrell, 1982). In that regard, this article makes a contribution by exclusively addressing the ensuing research questions: (1) how do prospective mathematics teachers reason about trigonometry concepts? (2) What misconceptions are implicit in prospective mathematics teachers' reasoning about trigonometric concepts? (3) What is the likely source of the misconceptions demonstrated by prospective mathematics teachers?

\section{LITERATURE AND THEORY}

As earlier intimated, the teaching of mathematics at school level should be conducted with a goal in mind of learners acquiring conceptual understanding. Teachers do play a critical role in the process of learners' acquisition of conceptual understanding. In this regard, mathematics teachers' lack of conceptual understanding could have a negative bearing on their pupils' understanding of concepts. Mathematics teachers who have conceptual understanding of the content they teach are well positioned to prepare assessment tasks that do not merely allow learners to recall mathematical facts. Such teachers are likely to administer appropriate formative assessments and accord their learners opportunities to think critically, and develop mathematical arguments, and abilities to justify reasoning (Malambo, 2015). The implication is that mathematics teachers cannot effectively teach and assess subject matter they have no in-depth understanding therein.

Besides, mathematics concepts are usually built on other concepts and consequently teachers' failure to acquire in-depth understanding of particular concepts may have a negative effect on their understanding of other related concepts. It should also be acknowledged that a teacher's understanding of a mathematics topic in isolation of other related mathematics topics may not be sufficient for effective teaching. This is so especially that there are mathematics concepts which appear similar on the surface, but are conceptually different.

One of the barriers to learners' conceptual understanding of concepts are what researchers generally call misconceptions. Review of literature revealed that there are studies which have been conducted on the subject of misconceptions in different mathematics topics such as calculus, fractions and trigonometry (Hammer, 1996; Muzangwa \& Chifamba, 2012; Ojose, 2015; Pesen, 2007; Tuna, 2013). The findings of such studies suggest that students do exhibit misconceptions. Moreover, comprehensive evidence of students and pre-service teachers' demonstration of misconceptions in various mathematics topics is summarized in an article focusing on the review of studies on misconceptions (Yasin, 2017).

Researchers have provided definitions in the quest to clarify what misconceptions entail (Hammer, 1996; Ojose, 2015; Yasin, 2017). Hammer (1996) contends that the term 'misconceptions' includes views which are different or are not consistent with the perspectives advanced by individuals who are deemed experts in a specified subject area. On the other hand, Yasin (2017) posits that misconceptions are basically misunderstandings of concepts. This perspective is consistent with Ojose's (2015) idea that misconceptions are misunderstandings and misinterpretations of concepts. The current article adopts the perspective, on misconceptions, espoused by Ojose as it is considered comprehensive. Although experts in mathematics subject matter are expected to recognize misconceptions easily, I hold an opinion that there are instances when misconceptions are subtle and not easily detectable. Arguably, misconceptions may solely be implied in one's written or verbalized reasoning thereby requiring close analysis of the written text or verbalized views for detection. I therefore propose, in this article, to use the phrase 'implicit misconceptions' to mean misunderstandings and misinterpretations which are implied in prospective mathematics teachers' reasoning about concepts.

Research evidence exists of Zambian university student teachers lacking in relational understanding of school mathematics concepts (Malambo, 2015, 2020; Malambo et al., 2018, 2019; Marbán \& Sintema, 2020). However, there is a lack of research literature, in the Zambian context, which centers on prospective teachers' implicit misconceptions as they reason about trigonometric concepts. Against this background, this article is intended to fill that gap by relating the findings of an investigation which was based on the following trigonometric concepts: trigonometric equations, values of trigonometric expressions, angles of non-right angled triangles, and characteristics of the sine and cosine functions.

Trigonometric equations are unique in the sense that unlike conventional algebraic equations, their solutions are not mere numbers but angles. This conceptual difference carries a likelihood of students assuming that trigonometric equations could be treated in exactly the same way algebraic equations such as linear and quadratic equations are solved. Likewise, trigonometric expressions and functions are defined on angles and therefore cannot be evaluated in the same manner algebraic terms and functions are processed. These are some of the aspects which prospective teachers of mathematics should be knowledgeable of and it is important to assess how they reason about such.

Brousseau's (1997) theory of didactical situations partially forms the basis for understanding the implicit misconceptions in prospective mathematics teachers' reasoning about trigonometry concepts. This theory indicates that apart from errors arising from ignorance, uncertainty and chance, errors could be the result of previous successful knowledge which is then presently shown to be false or not adapted. The aspect of the theory which is relevant to this article is one that relates to the idea of 'obstacle'. An obstacle is conceptualized as a manner 
of knowing which is effective in particular situations and yet simultaneously promotes manifestation of errors in other settings. Notwithstanding that the theory of didactical situations articulates the idea of obstacles from three perspectives namely; ontogenic, didactical, and epistemological (Brousseau, 1997), the current article's focus is on didactical obstacles. This preference is motivated by the fact that didactical obstacles arise from instructional choices which I consider to be a relevant aspect in the work of teachers. What follow is a description of the methodological issues that are applicable to this article.

\section{METHODOLOGY}

The study upon which this article is reliant followed a qualitative approach and employed a case study (Creswell, 2012; Merriam, 2009; Nieuwenhuis, 2014). Choices of this approach and the specified design were grounded on the desire to access the depth of and reasons for the prospective teachers' implicit misconceptions as they reasoned about trigonometry concepts. The sample consisted of three prospective teachers who majored in mathematics and were in their final year of study at a Zambian university. In order to bring out illuminating data from the prospective teachers' reasoning as exhibited in the principal study, an extreme case technique based on purposive sampling was used to select the participants (Creswell, 2012; Merriam, 2009). This technique is concerned with the choice of participants who manifest radical characteristics.

The three prospective mathematics teachers answered diagnostic pencil and paper questions and thereafter participated in individual semi-structured interviews. Administered questions deserved partial credit and were prepared after rigorous document analyses of the materials relevant to the Zambian secondary school mathematics curriculum (Bostock, 2000; Buckwell, 1996; Channon, 1994, 1996; Fuller, 1986; Laridon, 1995; Ministry of Education, 2013b; Redspot, 2013; Talbert, 1995). In addition, the questions were aligned to the descriptors of the categories of the core study's conceptual framework (Malambo, 2015). In that conceptual framework, subject matter knowledge was categorized as Common Content Knowledge (CCK), and Specialized Content Knowledge (SCK) (Ball et al., 2008). Several descriptors were conceptualized for CCK and SCK. For purposes of this article, a descriptor of CCK applicable to the diagnostic questions (Figure 1) is one that required prospective teachers to correctly solve trigonometric questions. The descriptor of SCK applicable to interview questions relates to assessment of prospective teachers' ability to coherently explain trigonometric concepts and provide appropriate justifications for their reasoning.

During the test instrument development process, a pilot study was conducted using a draft test, and expert judgment sought prior to compilation of the final diagnostic questions. These endeavors were intended to facilitate content and face validity of the data collection instrument. The applicable diagnostic questions for this article are shown in Figure 1.

1. Calculate the value of $\beta$ given that $\cos \beta=$ $-\cos 64^{\circ}$ for $90^{\circ}<\beta<180^{\circ}$.

2. Without the use of a calculator, find the value of $\sin 315^{\circ}$.

3. Giving the answer to one decimal place, calculate the smallest of the angles of a triangle whose sides are in the ratio $2: 4: 5$.
4. The table of values below represents a function $f$ for $0^{\circ} \leq \theta \leq$ $360^{\circ}$.

\begin{tabular}{|c|c|c|c|c|c|}
\hline $5 . \quad \theta$ & $0^{\circ}$ & $90^{\circ}$ & $180^{\circ}$ & $270^{\circ}$ & $360^{\circ}$ \\
\hline$f(\theta)$ & 0 & 1 & 0 & -1 & 0 \\
\hline
\end{tabular}

State the range and period of the function $f$.

Figure 1. Administered questions

To facilitate credibility of the findings, the researcher administered the questions to the participants at the same time and venue. Since assessment items were based on subject matter in which the researcher is knowledgeable, qualitative item by item analyses were conducted on the prospective teachers' answer scripts. Subsequently, the three prospective teachers were subjected to individual semi-structured interviews which focused on the trigonometric concepts composing the written diagnostic questions. The act of interviewing participants who wrote diagnostic questions is consistent with the views of Yasin (2017) who contends that "one of the most appropriate ways to determine students' misconceptions is collecting qualitative data through interview or observation, since they provide in-depth information about students' knowledge" (p. 28).

The interview schedule for the primary study underwent the processes of a pilot study and expert judgment to enhance its trustworthiness. The interview questions were exploratory in nature and in this regard were characterized by probing (Bell, 2014; Cohen et al., 2000). Resultant interview transcripts were explored for segments suggesting implicit misconceptions in respect of the participants' responses to the interview questions. Finally, findings from the diagnostic questions and interviews were compared to determine corroborations and discrepancies.

\section{RESULTS}

In this segment, results that were obtained through the questions in Figure 1 and semi-structured interviews are presented and analysed. To promote anonymity of the participants, the following pseudonyms are used: Jakopo, Makonka, and Asombo. For each question, I will first and foremost present what was expected of the prospective teachers and then were necessary a sample calculation as made by prospective teachers will be provided. This will be succeeded by analyses of the solution. Concurrently, interview data and analyses relating to how prospective teachers reasoned about the concepts involved will be given. I now provide results based on question 1 in Figure 1.

In question 1 , it was expected of the prospective teachers to have knowledge that the cosine ratio has negative values in the second quadrant where the solution of the trigonometric equation $\cos \beta=$ $-\cos 64^{\circ}$ for $90^{\circ}<\beta<180^{\circ}$ lies. Prospective teachers were expected to have understanding that the required angle was obtuse and that it is a supplementary angle to $64^{\circ}$. Nonetheless, a scientific calculator can be used to resolve the trigonometric equation. Jakopo, Makonka, and Asombo demonstrated inability to provide the correct solution to question 1. For example, Jakopo presented the incorrect calculation denoted Figure 2. 


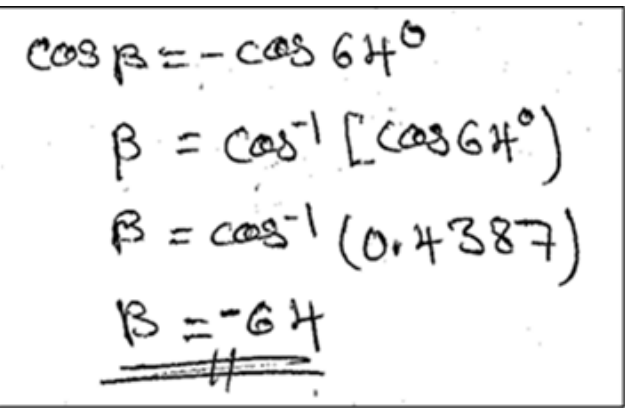

Figure 2. Answer to question 1 provided by Jakopo

The third line of Figure 2 suggests that Jakopo used a calculator to solve the trigonometric equation. Although the prospective teacher had a generic idea concerning the use of a calculator to compute an angle (based on the third line), the overall calculation illustrates a lack of depth of understanding. Jakopo, without justification, eliminated the negative sign associated with $\cos 64^{\circ}$ in the second line of Figure 2. This could have been either by omission or due to lack of understanding. In order to acquire insight of the participant's thought processes; Jakopo was requested to explain what question 1 is assessing. Initially, the prospective teacher indicated that the question involved 'the property of angles' and that it dealt with linking trigonometric ratios to quadrants. The participant was asked to clarify what was meant by 'the property of angles'. To this query, Jakopo indicated that the said phrase referred to the 'sign of the cosine ratio' in the second quadrant. However, Jakopo erroneously added that the cosine ratio is positive in the second quadrant. This supplementary view provided speculative insight into the unspoken reason why the negative sign associated with $\cos 64^{\circ}$ may have been dropped in the second and third lines of Figure 2. Consequently, Jakopo was shown Figure 2 and probed as follows:

Researcher $(R)$ : I want you to share with me how you calculated for the value of $\beta$.

Have a look at the answer that you gave [Figure 2]; carry me through your calculation, how you got the value of $\beta$.

Jakopo (J) : Mmm okay here I just looked at the cos because cos, $\cos$, cos; this side were common so it meant that since here there was $\cos 64^{\circ}$ it meant that even $\beta$ was $64^{\circ}$.

$R$ : $\beta$ was equal to $64^{\circ}$ ?

$J$

: But because of the coefficient negative, my angle was $\beta=-64$.

Jakopo's explanations in the preceding excerpt correlate with an implication of Figure 2 suggesting inability to interpret the interval $90^{\circ}<\beta<180^{\circ}$. Apparently $\beta=-64^{\circ}$ lies outside the prescribed solution interval90 $20^{\circ}<<180^{\circ}$. Besides, the prospective teacher's reasoning confirms inability to differentiate clockwise and anti-clockwise angle rotations. In explaining Figure 2, the prospective teacher initially ignored the negative sign associated with $\cos 64^{\circ}$ and only reverted to it at the end. It seems that the negative sign was considered as a mere coefficient of $\cos 64^{\circ}$ with inconsequential effect on resolution of the equation. Most revealingly, the excerpt confirms that Jakopo reasoned that the trigonometric equation could be solved in exactly the same manner an ordinary algebraic linear equation can be solved. For example, and while the explanation is incoherent, the prospective teacher understood the word $c o s$ as a constant which needed to be divided on both sides of the trigonometric equation. These discoveries are a clear demonstration of the prospective teacher's lack of understanding of the conceptual difference between algebraic linear equations and trigonometric equations. In addition, the participant's explanations suggest a lack of understanding of trigonometric ratios. Whereas $\cos$ is a mere word, $\cos 64^{\circ}$ is a trigonometric ratio defined on an angle $64^{\circ}$.

Despite being aware that question 1 required calculation of the value of angle $\beta$, Makonka did not provide a calculation. This failure suggested a lack of understanding of what was involved in the resolution of the equation. During the interview Makonka claimed that it was impossible to solve the equation $\cos \beta=-\cos 64^{\circ}$ for $90^{\circ}<$ $\beta<180^{\circ}$ in its current form. The student teacher contended that the equation could only be solved if it had been expressed in terms of both the sine and cosine ratios. This revelation prompted the researcher to request Makonka to cite an example of a trigonometric equation expressed in terms of sine and cosine ratios for which it was possible to solve. The student teacher presented the equation $\cos \beta=\sin 64^{\circ}$ and was consequentially asked to explain how such an equation could be solved. The discussion progressed as highlighted in the following excerpt:

$R \quad$ : How could you have solved the equation $\cos \beta=$ $\sin 64^{\circ}$ ?

Makonka (M) : I would have put cos there, cos there, then I would remain with $\beta$.

$R \quad$ : What do you mean 'I would have put $\cos$ ' [there]?

M : I would divide by the inverse of (pauses), multiply by the inverse of cos.

$R \quad$ : What is the inverse of cos there?

M : I more like divide by $\cos$ here even here by $\cos$ it will give me this $\sin$ over cos, which is $\tan 64^{\circ}$.

The foregoing suggests that Makonka had an implicit misconception that $\cos ^{-1} \theta=\frac{1}{\cos \theta}$. Although it seems that the student teacher knew that the tangent ratio is a result of dividing the cosine ratio into the sine ratio, Makonka just like Jakopo did not reason that $\cos$ is usually associated with an angle and that $\cos \beta$ is a trigonometric ratio. Makonka demonstrated superficial understanding by intimating that $\beta=\frac{\cos \beta}{\cos }$ and $\frac{\sin 64^{\circ}}{\cos \tan 6^{\circ}}$. Such reasoning suggests that $\cos$ was treated as a constant and a coefficient of $\beta$. Moreover, Makonka contended that in order to determine the value of $\beta$; the expression $\tan 64^{\circ}$ needed to be evaluated using a calculator. By implication, this student teacher thought that the only trigonometric equations which can be solved without the aid of a calculator are those that involve special angles such as $60^{\circ}$ and $45^{\circ}$. What follow is data and analyses relating to the prospective teachers' solutions and reasoning concerning question 2 .

Question 2 assessed participants' understanding of applicable trigonometric identities and special angles which could be employed to evaluate the trigonometric expression $\sin 315^{\circ}$. Successful resolution of the item required understanding of the quadrants and which trigonometric ratios are positive or negative in each one of the four quadrants. Jakopo and Makonka failed to provide solutions to question 2. Similarly, during the interviews these two student teachers could not explain their understanding of question 2. Asombo provided a written solution to question 2, denoted Figure 3, but could not explain that answer. 


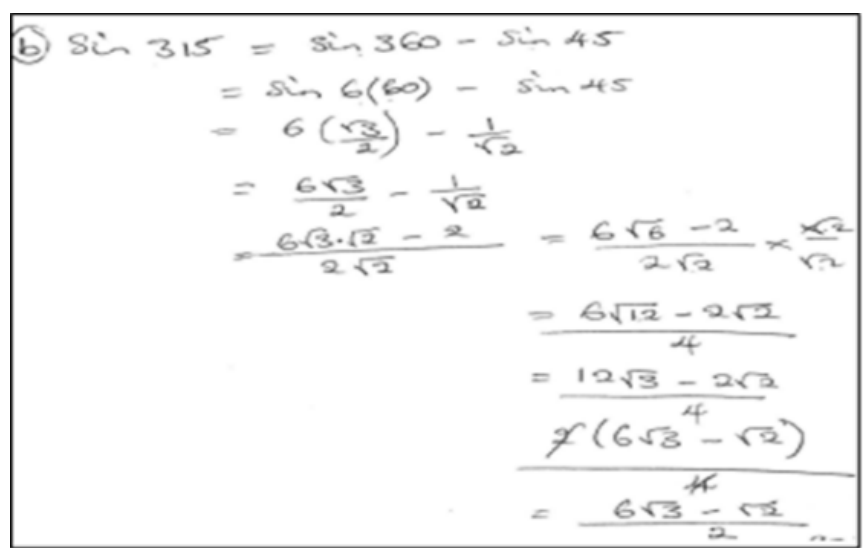

Figure 3. Asombo's answer to question 2

$$
\begin{aligned}
& 2: 4: 50 \\
& =\frac{2}{11} \times 180 \\
& =32.7^{\circ}
\end{aligned}
$$

Figure 4. Jakopo's answer to question 3

Asombo's calculation suggests lack of in-depth understanding of trigonometric ratios and demonstrates incapacity to evaluate $\sin 315^{\circ}$ without use of a calculator. The student teacher incorrectly understood that $\sin 315^{\circ}=\sin 360^{\circ}-\sin 45^{\circ}$. This conception illustrates an implicit misconception that trigonometric expressions can be subtracted in the same way whole numbers or algebraic like terms are subtracted. Whereas the student teacher had a correct idea that $\sin 45^{\circ}=\frac{1}{\sqrt{2}}$, Figure 3 suggests a misconception that $\sin \left[6 \times 60^{\circ}\right]=$ $6\left(\frac{\sqrt{3}}{2}\right)$. The student teacher did not know that $6\left(\frac{\sqrt{3}}{2}\right)=6 \times \sin 60^{\circ}$ which is not equal to $\sin \left[6 \times 60^{\circ}\right]$. These observations are indicative of the disconnected nature of the understanding of the student teachers.

The essence of question 3 was to investigate the student teachers' understanding of the cosine rule when its use is depicted in an unfamiliar context. It was also the intention to establish whether or not the participants could connect the components of a ratio of the sides of a triangle to the actual lengths of the sides of the triangle. Equally, the question assessed student teachers' knowledge concerning the position of the smallest angle of a triangle in relation with the lengths of its sides. Furthermore, student teachers' capacity to express an answer to specified number of decimal places was investigated.

Whereas Asombo did not present a written answer and could not explain question 3, Jakopo and Makonka presented similar, but incorrect calculations. Figure 4 is a reproduction of the calculation by Jakopo.

Based on Figure 4, Makonka and Jakopo could not associate the components of the given ratio to the lengths of the sides of the triangle. The student teachers interpreted the ratio of the sides of a triangle as a ratio of the angles of the triangle. Moreover, Figure 4 suggests the student teachers' lack of understanding that the cosine rule was applicable to question 3. During interviews, Makonka affirmed the calculation similar to Figure 4 and argued that it was the 'direct way of finding ratios'. The student teacher posited that there was no alternative method for resolution of question 3. Besides, Makonka explained that the component 2 of the ratio 2: $4: 5$ was utilized to calculate the required angle because it is the smallest of the three components. Jakopo was shown Figure 4 and probed as follows:

$R$ : What did you understand of that question [question 3]?

$J$ : (Laughs), I think afterwards that is when I thought that I was supposed to draw a triangle.

$R$ : You were supposed to draw a triangle?

$J$ : A triangle, yes, then I say one side it will be two, then the other one it will be four and five and using the cosine rule I find the angle for the smallest which is two.

Jakopo's sentiment: 'I find the angle for the smallest which is two' is unfounded. However, the impression created in the preceding extract is that the student teacher had a change of perspective during the interview. When interviewed alongside Figure 4 the student teacher's view was that the cosine rule should have been applied on question 3 . The student teacher was queried for additional insight:

$R$ : Are you saying [that] the components of the ratio [2:4:5] are actually the lengths of the sides of the triangle?

$J$ : Yes, umm but I think on that day I did this [points at Figure 4], I added this (pauses) then I got the 2 then times $180^{\circ}$ it gave me this $\left[32.7^{\circ}\right]$. But I would have tested even for these other numbers [4 and 5].

$R$ : But today you are talking of the cosine rule?

$J \quad$ : Yah, I think even this one [points at Figure 4] can work.

$R$ : So the cosine rule or the same method you used in the test [Figure 4] would still work?

$J \quad$ : Yes, aha.

The foregoing suggests that Jakopo's change of perspective was grounded on superficial understanding. By affirming that uses of either the cosine rule or the method in Figure 4 were appropriate, Jakopo demonstrated conflicted understanding. Despite the correct view that the elements of 2:4:5 are lengths of the triangle described in question 3 , the student teacher believed implicitly that the components of this ratio were fractions of $180^{\circ}$ (a sum of interior angles of a triangle).

Question 4 depicts the sine function denoted $f$ and defined on the domain $0^{\circ} \leq \theta \leq 360^{\circ}$. Furthermore, $f$ is represented as a table of values. The purpose of the question was to assess whether or not the prospective teachers were capable of recognizing a sine function expressed in tabular form. It was also the intention to understand how university trained student teachers reasoned about the characteristics of the sine function. The data accessed suggested that the student teachers could not identify the sine function when expressed as a table of values. Besides, they gave wrong answers for the 'period' and 'range' of the function $f$. For example, a student teacher incorrectly posited that the 'range' and 'period' of the function $f$ are $0,1,-1$ and $180^{\circ}$ respectively. By implication, that student teacher was ignorant of the fact that the range of the sine function is continuous. The period presented was for the tangent function and not the sine function. Either the student teacher thought that $f$ was a tangent function or had no knowledge of the period of the sine function. Another student teacher stated that the range of $f$ is $0^{\circ} \leq \theta \leq 360^{\circ}$ and that its period is 'from -1 to $1^{\prime}$. These answers suggest that the student teacher lacked the correct understanding of the concepts of domain, range and period of the sine function. 
During interviews, the student teachers exhibited several implicit misconceptions as regards to the characteristics of the sine and cosine functions. A few excerpts in that regard are provided in the ensuing section:

$$
R \quad: \text { What is the range of } f(\theta)=\sin \theta \text { ? }
$$

Asombo (A) : $\sin \theta$ will actually range from $0^{\circ}$ to $360^{\circ}$ then from $360^{\circ}$ to uh should be $720^{\circ}$.

Asombo's view as expressed above validates a misconception that the range of a sine function is composed of angles. This corroborates the student teachers' written answers to question 4 . The interview discussion with Jakopo went as follows:

$$
\begin{aligned}
& R \quad: \text { What is the range of } f(\theta)=\sin \theta \text { ? } \\
& J \quad: \text { The range [of } f(\theta)=\sin \theta] \text { is } 1 ;-1 \text { and } 1 . \\
& R \quad:-1 \text { and } 1 \text { ? } \\
& J \quad: \text { Yes. }
\end{aligned}
$$

Jakopo did not consider the range of a sine function to be a continuous interval. The student teacher was of the implicit view that the sine function is discontinuous over some of the real angles. It also seems that the student teacher had a misunderstanding that the minimum and maximum values of the sine function were actually its range. In respect of extreme values of the sine and cosine functions, the student teachers revealed misconceptions as the following excerpt attests:

$R$ : Let me ask you this question: what's the maximum value of $f(\theta)=\sin \theta$ ?

$M: 2 \pi$.

$R$ : Why $2 \pi$ ?

$M$ : Because that is the complete revolution.

$R$ : Okay, what is the minimum value of $f(\theta)=\sin \theta$ ?

$M:$ It is $\pi$.

$R$ : Do you have a justification why it is $\pi$ ?

$M:$ No (laughs). I can just tell from the graph of $f(\theta)=\sin \theta$.

The interview with Makonka intimated the student teacher's incapacity to distinguish the concept of extreme values of trigonometric functions from the elements of domains upon which such functions are defined. Makonka believed without justification that the maximum value of a sine function is equivalent to the number of radians composing a revolution. As regards the minimum value of the sine function, the student teacher's position was that it was equal to the number of radians equivalent to half of a revolution. Makonka argued that the graph of the sine function is what justified this view. When requested to draw the sine curve, the student teacher presented Figure 5. Interestingly, Figure 5 suggests a minimum value of -1 with a domain ranging from 0 to $2 \pi$ radians.

Figure 5 and Makonka's orally posited views suggest conflicted understanding. The student teacher believed implicitly that the extreme values of the sine function are the angles at which the trigonometric function's curve intercepts the horizontal axis. Most likely, the student teacher could have perceived extreme values to be synonymous with two of the zeros of $f(\theta)=\sin \theta$ in the domain $0^{\circ} \leq \theta \leq 360^{\circ}$. This perspective is plausible in that angles $2 \pi$ and $\pi$ which Makonka indicated as being the maximum and minimum values respectively give a value of zero for the sine function (though not the only ones). In order

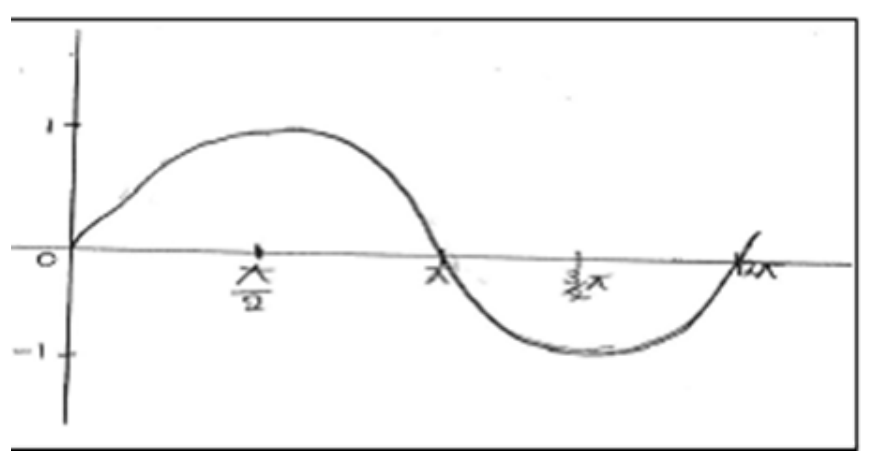

Figure 5. Sine curve as drawn by Makonka

to acquire insight, Makonka was probed concerning the extreme values of the cosine function:

$R$ : What is the maximum value of $\cos \theta$ ?

$M$ : It is positive $360^{\circ}$.

$R$ : Supposing a pupil gave you -20 as one of the values for $\cos \theta$. How would you take that?

$M$ : Can you find a negative value [for $\cos \theta$ ]? Unless you check if it is possible that the (stammers), the cosine inverse of the -20 can be found, because sometimes you find that those, they don't exist.

$R \quad$ : What does not exist?

$M$ : Certain values say negative something like that; I don't know (laughs).

The preceding excerpt confirms that Makonka consistently believed that extreme values of trigonometric functions were actually the zeros of the functions. When asked to justify the incorrect view that $360^{\circ}$ is the maximum value of $\cos \theta$, the student teacher claimed that it is because the complete revolution ends at $360^{\circ}$. Makonka was not certain whether the cosine function can assume negative values or not. The student teacher was hypothetically asked whether or not $\cos \theta \operatorname{could}$ assume a value of -20 . Makonka contended that it was necessary to first of all determine the existence or none existence of $\cos ^{-1}(-20)$ before taking a position. Although $\cos \theta=-20$ is incorrect, it is the student teacher's expression of surprise that the cosine function could assume negative values which suggests shallow understanding of the cosine function.

\section{DISCUSSION}

Analyses of the data derived from the student teachers' answers to diagnostic and interview questions brought to light prospective teachers' implicit misconceptions as they reasoned about trigonometric concepts. The prospective teachers could not link correctly their previously acquired mathematical knowledge to trigonometric concepts. They were unable to apply appropriately mathematics knowledge learned through topics such as algebraic equations and expressions, and ratios to solve correctly trigonometric questions. For example, student teachers' reasoning suggested an implicit misconception that trigonometric equations could be solved in exactly the same way ordinary algebraic linear equations are solved. The student teachers were unable to differentiate the trigonometric equation $\cos \beta=-\cos 64^{\circ}$ for $90^{\circ}<\beta<180^{\circ}$ from conventional algebraic linear equations. Likewise, the student teachers could not 
demonstrate understanding that whereas final answers of ordinary algebraic equations are mere numbers; trigonometric equations have angles for solutions. Furthermore, the participants demonstrated lack of understanding that cos is not a mere word, but that it is usually associated with an angle (trigonometric ratio). This was exemplified by a student teacher who claimed that $\beta=\frac{\cos \beta}{\cos }$. Arguably, the student teacher considered cos as a constant and coefficient of an angle which could be divided into each term of a trigonometric equation. Student teachers treated angles associated with terms of a trigonometric equation in similar manner variables in an algebraic equation are considered. Even though dividing terms with coefficients of variables can give correct values in the context of linear algebraic equations, such practices cannot be applied generally to the trigonometric equation $\cos \beta=-\cos 64^{\circ}$.

The student teachers reasoned that trigonometric expressions could be processed in the same way ordinary algebraic like terms are simplified. A student teacher, for example, incorrectly expressed $\sin 315^{\circ}$ as $\sin 360^{\circ}-\sin 45^{\circ}$ and another one erroneously reasoned that $\sin \left(6 \times 60^{\circ}\right)=6 \times \sin 60^{\circ}$. Such reasoning suggests that the student teachers had superficial understanding of trigonometric identities. In addition, it seems that the student teachers reasoned that trigonometric terms are the same as real numbers. Another striking misconception relates to a student teacher who reasoned that $\cos ^{-1} \theta=\frac{1}{\cos \theta}$. This finding suggests that the student teacher's view was that what is applicable to the topic indices holds for inverse trigonometric functions. Under indices, an arithmetic term, for example, $3^{-1}$ is equivalent to $\frac{1}{3^{1}}=\frac{1}{3}$. This, however, does not hold for an inverse trigonometric function $\cos ^{-1} \theta$ in which -1 is not the same as the index -1 of $3^{-1}$. The student teachers' misconceptions as highlighted above are consistent with some of the findings of an experimental study by Tuna (2013). Issues discussed above point to the student teachers' inability to understand conceptual relationships and differences. Through repeated success at resolving questions using inappropriate procedures, student teachers do develop error patterns which subsequently become generalized misconceptions.

This article shows that student teachers were familiar with 'sharing' or 'dividing' quantities in a given ratio. While student teachers had memorized the procedure of dividing quantities in a given ratio, their understanding of the concept of ratio was not connected across contexts. They, for instance, could not contextualize the ratio 2: $4: 5$ of the sides of a triangle. Apparently, a ratio invoked in student teachers' minds a practice of 'dividing' or 'sharing' a quantity. In that regard, a ratio of the sides of a triangle prompted the 'sharing' of the sum of interior angles of the triangle $\left(180^{\circ}\right)$. Moreover, the student teachers could not demonstrate understanding that the smallest of the angles of a triangle is usually the one which is opposite to the shortest side of a triangle. Furthermore, student teachers had a fragmented repertoire of knowledge and consequently could not reason about application of the cosine rule in relation to question 3 of Figure 1. This was the case notwithstanding that the student teachers recited correctly the conditions under which the cosine rule can be applied. The student teachers exhibited an aptitude to reason within familiar contexts only and not across contexts. Thus, the student teachers could not connect with ideas acquired previously when such ideas were presented in an unfamiliar context.

Student teachers were of the implicit view that extreme values of the sine and cosine functions are synonymous with elements of the domains of such functions. The student teachers' reasoning demonstrated conflicted understanding in respect of the concept of 'range' and 'period' of a trigonometric function. For example, the 'period' was understood to consist of elements of a 'range' while a 'range' was understood to consist of elements of a 'domain'. These findings suggest that the student teachers had wrong conceptions of the ideas of domain, range and period of the sine and cosine functions.

Largely, the findings discussed in this article corroborate findings of previous studies to the extent that mathematics student teachers' understanding of school mathematics concepts is superficial (Akkoc, 2008; Malambo, 2020; Malambo et al., 2018, 2019; Marbán \& Sintema, 2020). The findings are also consistent with the theory of didactical situations (Brousseau, 1997). It would appear that the misconceptions demonstrated in the student teachers' reasoning were a consequence of previously acquired knowledge on solutions of linear algebraic equations, indices and ratios. That knowledge, unfortunately, proved false in the context of trigonometric concepts. The student teachers' reasoning suggested instructional obstacles as they reasoned about trigonometric concepts. Their success at previously acquired knowledge such as that of resolution of linear equations, ratios, and indices promoted the manifestation of misconceptions in the context of trigonometric concepts.

\section{CONCLUSION}

This article has postulated a view that prospective mathematics teachers' reasoning about trigonometric concepts was superficial. In this regard, implicit misconceptions were detected in prospective mathematics teachers' reasoning about selected trigonometric concepts. The paper and pencil calculations corroborated the interview findings in that the student teachers' reasoning demonstrated didactical obstacles. There was a generic sense in which student teachers' reasoning suggested that procedures and practices which are applicable to other mathematics concepts consequentially apply to trigonometric concepts. Student teachers had mastered procedural knowledge in other topics without substantially understanding the conceptual connections and dissimilarities of those topics to trigonometric concepts. A possible source of implicit misconceptions in prospective mathematics teachers' reasoning about trigonometric concepts seemed to be their deficiency to understand conceptual relationships and differences among mathematics topics.

The foregoing scenarios could be a reflection of pedagogic practices, in teacher education, that project mathematics subject matter as being fragmented into topics. Such practices are consistent with situations where student teachers are rarely enabled to appreciate what I have conceived as the 'connectivity' of mathematics concepts. While conceptual relationships do exist in mathematics, there are equally conceptual differences among mathematics concepts. It is therefore recommended that conceptual relationships and differences of trigonometric ideas and concepts in other topics such as algebraic linear equations, and indices be recognized and discussed during teacher training. Thus, it is essential for mathematics teacher educators to devise didactic practices which provide opportunities for enhancement of student teachers' acquisition of in-depth understanding of conceptual relationships and differences among mathematics topics. This can be done without overlooking the significance of allowing student teachers to work with mathematics ideas in both familiar and unfamiliar 
contexts. It is also recommended that mathematics teacher educators be deliberate, as they train teachers of mathematics, in their efforts to prevent didactical obstacles. This proposal is plausible in light of research evidence which suggests that student teachers' inability to comprehensively understand mathematics concepts is linked to the manner in which they are trained (Malambo, 2015).

Funding: The author received no financial support for the research and/or authorship of this article.

Declaration of interest: Author declares no competing interest.

Data availability: Data generated or analysed during this study are available from the author on request.

\section{REFERENCES}

Akkoc, H. (2008). Pre-service mathematics teachers' concept images of radian. International Journal of Mathematical Education in Science $\mathcal{E}$ Technology, 39(7), 857-878. https://doi.org/10.1080/0020739080 2054458

Ball, D. L., Thames, M. H., \& Phelps, G. (2008). Content knowledge for teaching what makes it special? Journal of Teacher Education, 59(5), 389-407. https://doi.org/10.1177/0022487108324554

Bell, J. (2014). Doing your research project: A guide for first-time researchers: McGraw-Hill Education (UK).

Bostock, L., \& Chandler, S. (2000). Core maths for advanced level. Nelson Thornes.

Brousseau, G. (1997). Theory of didactical situations in mathematics Kluwer.

Buckwell, G. (1996). Mastering advanced pure mathematics. Macmillan Press Ltd. https://doi.org/10.1007/978-1-349-13551-6

Channon, J. B., Smith McLeish, A., Head, H. C., Macrae, M. F., \& Chasakara, A. A. (1994). New general mathematics 4. Longman Group Limited.

Channon, J. B., Smith McLeish, A., Head, H. C., Macrae, M. F., \& Chasakara, A. A. (1996). New general mathematics 3. Longman Group UK Limited.

Cohen, L., Manion, L., \& Morrison, K. (2000). Research methods in education (Fifth Ed.). Routledge Falmer.

Creswell, J. W. (2012). Educational research planning, conducting, and evaluating quantitative and qualitative research (4th Ed.). Pearson Education.

Ferguson, R. L. (2007). Constructivism and social constructivism. Theoretical frameworks for research in chemistry/science education, 2849.

Fuller, G., \& Tarwater, D. (1986). Analytic geometry. Addison-Wesley Publishing Company.

Hammer, D. (1996). More than misconceptions: Multiple perspectives on student knowledge and reasoning, and an appropriate role for education research. American Journal of Physics, 64, 1316-1325. https://doi.org/10.1119/1.18376

Laridon, P., Brink, M., Fynn, C., Jawurek, A., Kitto, A., Myburgh, M., Pike, M., Rhodes-Houghton, H., \& Rooyen, R. (1995). Classroom mathematics standard 9/grade 11/level 11 (2nd Ed.). Heinemann Publishers.
Malambo, P. (2015). Exploring Zambian mathematics student teachers content knowledge of functions and trigonometry for secondary schools (University of Pretoria). http://hdl.handle.net/2263/52943

Malambo, P. (2020). Pre-service mathematics teachers' nature of understanding of the tangent function. JRAMathEdu (Journal of Research and Advances in Mathematics Education), 5(2), 105-118. https://doi.org/10.23917/jramathedu.v5i2.10638

Malambo, P., Putten, S., Botha, H., \& Stols, G. (2018). Mathematics student teachers' understanding of trigonometry for secondary schools. Nov 2018 11th Annual International Conference of Education, Research and Innovation, Spain. https://doi.org/10.21125/iceri.2018.0748

Malambo, P., Putten, S., Botha, H., \& Stols, G. (2019). Dysfunctional functions: The case of Zambian mathematics education students. Eurasia Journal of Mathematics, Science and Technology Education, 15(1), em1651. https://doi.org/10.29333/ejmste/99510

Marbán, J., \& Sintema, E. (2020). Pre-service secondary teachers' knowledge of the function concept: A cluster analysis approach. JRAMathEdu (Journal of Research and Advances in MathematicsEducation), 5(1), 38-53. https://doi.org/10.23917/ jramathedu.v5i1.9703

Merriam, S. B. (2009). Qualitative research a guide to design and implementation (2nd Ed.). Jossey-Bass.

Ministry of Education. (2013a). Zambia education curriculum framework. Zambia Curriculum Development Centre.

Ministry of Education. (2013b). "O" level mathematics syllabus (Grades 10 to 12). Zambia Curriculum Development Centre.

Minstrell, J. (1982). Explaining the "at rest" condition of an object. The Physics Teacher, 20(1), 10-14. https://doi.org/10.1119/1.2340924

Muzangwa, J., \& Chifamba, P. (2012). Analysis of errors and misconceptions in the learning of Calculus by undergraduate students. Acta Didactica Napocensia, 5(2), 1-10.

Nieuwenhuis, J. (2014). Qualitative research designs and data gathering techniques. In K. Maree (Ed.), First steps in research (14th impression ed., pp. 69-97). Van Schaik.

Ojose, B. (2015). Students' misconceptions in mathematics: Analysis of remedies and what research says. Ohio Journal of School Mathematics, 72, 30-34.

Pesen, C. (2007). Students' misconceptions about fractions. Education and Science, 32(143), 79-88.

Redspot. (2013). Mathematics topical O level exam papers. Redspot Publishing.

Talbert, J. F., \& Heng, H. (1995). Additional mathematics pure and applied (6th Ed.). Longman Inc.

Tuna, A. (2013). The influence of the 5E model on the elimination of misconceptions on the subject of trigonometry. International Journal of Academic Research, 5(3). https://doi.org/10.7813/20754124.2013/5-3/A.3

Yasin, A. (2017). A review of research on the misconceptions in mathematics education. Education Research Highlights in Mathematics, Science and Technology, 21-31. 